\title{
Unidades habitacionais hoteleiras na Ilha de Santa Catarina: um estudo sobre acessibilidade espacial
}

\author{
Vera Helena Moro Bins Ely UFSC \\ Cristiane Silveira da Silva UFSC
}

RESUMO

Este artigo trata da avaliação das condições de acessibilidade espacial em unidades habitacionais (UHs), ditas acessíveis, de hotéis residenciais na ilha de Santa Catarina. Para tanto, visitas exploratórias permitiram o levantamento arquitetônico das UHs escolhidas e a análise de sua adequação aos parâmetros técnicos estabelecidos pela NBR 9050/2004. Entrevistas com diferentes usuários complementam o estudo na medida em que apontam as reais dificuldades enfrentadas por eles, devido às inadequadas soluções de acessibilidade presentes nos ambientes da rede hoteleira. Os métodos utilizados permitiram classificar os problemas de acessibilidade espacial segundo quatro componentes - orientação espacial, deslocamento, uso e comunicação - e relacioná-los às deficiências e habilidades dos diversos usuários. Encontrou-se maior prevalência de problemas ligados ao uso de mobiliários e equipamentos, os quais afetam a realização de atividades com conforto e independência. Verifica-se, também, que a NBR 9050/2004 ainda direciona seus parâmetros técnicos para atender principalmente deficientes físico-motores.

\section{Habitational units in hotels of the Island of Santa Catarina: a study about Spatial accessibility}

\begin{abstract}
This paper deals with the evaluation of the conditions of spatial accessibility in habitation units (UHs) considered accessible in residential hotels on the Island of Santa Catarina. For this purpose, exploratory visits allowed an architectonic survey of the chosen UHs and an analysis of their adjustment to the technical parameters established by NBR 9050/2004. Interviews with different users completed the study which highlighted the real difficulties faced by them due to inadequate solutions of accessibility present in the hotel network environments. The methods facilitated a classification of the problems of spatial accessibility according to four components - spatial orientation, displacement, use and communication - and related them to the abilities and disabilities of the various users. A higher prevalence of problems was found relating to the use of furniture and equipment, which affected the ability to undertake activities with comfort and independence. It is also confirmed that NBR 9050/2004 still focuses its main technical parameters on catering principally for people with physical-motor disabilities.
\end{abstract}

\section{KEYWORDS}

Spatial acessibility, residential hotel, social inclusion, limitation. 


\section{INTRODUÇÃO}

A acessibilidade de pessoas que sofrem algum tipo de dificuldade na realização de atividades, em ambientes internos ou espaços abertos, é um tema bastante recorrente. Diz respeito tanto aos profissionais ligados ao projeto arquitetônico e/ou urbano quanto aos ergonomistas, que se preocupam com as condições ambientais para a realização de tarefas. As barreiras, presentes nos ambientes, são exemplos de elementos que dificultam a acessibilidade espacial de diferentes usuários e, consequentemente, sua inclusão social.

Essas barreiras podem ser de origem física ou informacional. As barreiras físicas normalmente dificultam o deslocamento dos usuários e o uso de equipamentos presentes num ambiente. Assim como a ausência de uma rampa ou de um elevador impede o acesso a diferentes pavimentos para uma pessoa deficiente que utiliza cadeira de rodas, um posto de trabalho com mobiliário convencional dificilmente está adequado às dimensões corporais de um obeso ou de um idoso. Já as barreiras de informação são obstáculos tanto para a comunicação quanto para a orientação espacial. Uma placa com apenas informações escritas, sem nenhum pictograma, dificilmente é compreendida por um iletrado ou um estrangeiro. Se essas informações não estiverem em relevo ou em braile, não serão, também, percebidas por pessoas com deficiência visual.

Em vista disso, para que todos os usuários realizem atividades com conforto e segurança, é necessário que os profissionais, especialmente os responsáveis pelo projeto dos ambientes e equipamentos, conheçam as dificuldades ou limitações dos diferentes usuários para, então, poder identificar as barreiras presentes no ambiente de forma a eliminá-las.

Além dos espaços abertos - como passeios públicos e praças, entre outros -, todas as edificações deveriam ser acessíveis, tanto aquelas destinadas à moradia quanto ao trabalho e ao lazer. Este artigo enfatiza edificações que dão suporte ao lazer - os hotéis.

Foi instituído, em 2004, o Decreto n. ${ }^{0} 5.296$ que estabelece prazos para que edifícios públicos e coletivos tornem-se acessíveis. No caso dos hotéis, edificações de uso coletivo, o prazo esgotou-se em dezembro de 2008. Para cumprir as exigências da legislação e garantir que todos os diferentes usuários - incluindo deficientes - tenham bom desempenho na realização de atividades, é preciso que os hotéis ofereçam unidades habitacionais (UHs) acessíveis.
Este artigo vem, justamente, expor os resultados da verificação das reais condições de acessibilidade de duas unidades habitacionais, ditas acessíveis, de hotéis residenciais em Florianópolis. Essa tipologia hoteleira é muito utilizada por usuários não restritos à sazonalidade, pois é destinada a maior permanência do hóspede e oferece conforto e serviços diferenciados dos hotéis convencionais. O público é variado; pode ser o turista de eventos e negócios, o turista idoso, jovens casais, famílias ou pessoas que pretendam fixar residência por tempo limitado.

Neste artigo, além de avaliar as condições de acessibilidade espacial de UHs, pretende-se, também, identificar os principais problemas enfrentados pelos diversos usuários e relacioná-los a suas dificuldades e habilidades.

\section{ACESSIBILIDADE ESPACIAL}

Este estudo exigiu, primeiramente, uma definição do conceito de acessibilidade espacial e de seus componentes para, então, identificar quais usuários teriam mais dificuldades na realização de atividades e a que componentes tais dificuldades estão relacionadas.

O hotel, como um espaço que atende a diversos usuários, deve oferecer alternativas para seus hóspedes, conforme suas variadas necessidades, e ser acessível a todos. A definição do termo acessibilidade abrange muitos aspectos, que vêm sendo desenvolvidos ao longo de alguns anos e que até hoje sofrem modificações.

A NBR 9050 (2004, p. 2) refere-se à acessibilidade como "possibilidade e condição de alcance, percepção e entendimento para a utilização com segurança e autonomia de edificações, espaço, mobiliário, equipamento urbano e elementos". O conceito é, porém, muito mais amplo.

Para Dischinger (2004, apud OLIVEIRA, 2006),

\footnotetext{
“(...) a acessibilidade espacial é a possibilidade de compreensão da função, da organização e das relações espaciais que o ambiente estabelece, e a participação das atividades que ali ocorrem, fazendo uso dos equipamentos disponíveis com segurança e autonomia".
}

Muitos leigos consideram locais acessíveis aqueles em que uma pessoa que utiliza cadeira de rodas possa entrar 
e circular, mas se esquecem de que, além da deficiência físico-motora, existem as deficiências visual, auditiva e cognitiva, as quais exigem outras adequações espaciais. Não levam em consideração, igualmente, que não só as pessoas com deficiência podem sofrer restrições no desempenho de atividades devido às barreiras presentes nos ambientes, mas também idosos, gestantes, crianças, obesos, entre outros, exemplificam essa situação.

Com o intuito de compreender melhor a acessibilidade espacial de pessoas com deficiência e/ou que sofrem algum tipo de restrição, Dischinger et al. (2009) identificaram quatro componentes, a partir dos quais é possível avaliar o nível de acessibilidade do ambiente construído:

Orientação espacial: é a condição de compreensão do espaço que permite ao usuário orientar-se, de modo que saiba onde está, o que fazer e para onde ir, a partir de informação arquitetônica e adicional, como placas, mapas, layout do ambiente. É o que permite definir rotas para chegar a um determinado destino. Com o auxílio de pisos podotáteis, um deficiente visual tem condições de saber o caminho a ser percorrido e reconhecer a existência de obstáculos no seu entorno. Isso facilita, portanto, sua orientação e, como consequência, seu deslocamento seguro e independente. Os deficientes visuais são os usuários que mais apresentam problemas de orientação espacial.

$\rightarrow$ Deslocamento: é a possibilidade de deslocar-se de forma independente ao longo de percursos verticais e horizontais, os quais devem ser livres de obstáculos, confortáveis e seguros. Os usuários mais prejudicados com a ausência de tais percursos são os deficientes físico-motores (membros inferiores). Muitos deles fazem uso de cadeiras de rodas ou muletas; necessitam, portanto, deslocar-se de forma mais facilitada. Rampas e elevadores auxiliam o deslocamento desses usuários.

Uso: é a condição que permite o uso de equipamentos e a participação em atividades sem conhecimento prévio, com conforto e independência. Os equipamentos devem ser acessíveis a todos os usuários, de forma que possuam orientação quanto ao seu funcionamento e sejam de fácil uso. Dependendo das condições dos equipamentos, uma variedade muito grande de usuários pode apresentar, portanto, dificuldade no uso e, consequentemente, na realização de atividades. Crianças podem ter dificuldades de alcance; deficientes cognitivos e visuais, de compreensão do funcionamento de equipamentos; e pessoas que utilizam cadeiras de rodas, de aproximação em bancadas, por exemplo.
Comunicação: é a troca de informações entre pessoas ou entre pessoas e equipamentos de tecnologia assistiva, como terminais de computador, telefones com mensagem de texto, que permitam o ingresso aos ambientes, o uso de equipamentos e a participação nas atividades. Deficientes auditivos são os que mais apresentam dificuldades de comunicação, pois são raros os locais em que há a presença de intérprete de libras.

Para que a acessibilidade ocorra de forma efetiva, todos esses componentes espaciais devem ser atendidos: o indivíduo precisa ter acesso à informação, deslocar-se e utilizar equipamentos com independência, interagir com os demais e participar de atividades, o que torna possível sua inclusão na sociedade.

Uma pessoa com deficiência é julgada "não eficiente"

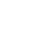

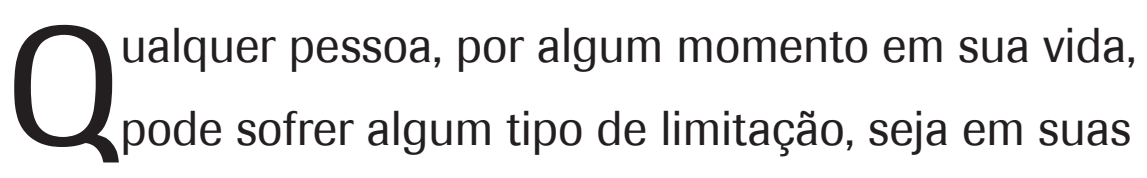

\section{capacidades físicas, cognitivas, seja nas psicológicas}

por não ser igual às pessoas "comuns". Essa atitude de desigualdade dificulta sua participação nas mais diferentes funções, como trabalho e lazer. No caso dos hotéis, certamente é frustrante para uma pessoa com deficiência saber que é quase impossível realizar atividades de forma independente, sem ajuda de alguém, ou talvez que o hotel não ofereça espaço adequado para seu deslocamento - no caso das pessoas que utilizam cadeira de rodas.

A deficiência é uma manifestação corporal ou a perda de uma estrutura ou função do corpo. A deficiência é, portanto, uma modificação fisiológica no organismo do indivíduo e pode ser dividida, segundo Dischinger (2004), em quatro grupos: deficiências sensoriais, cognitivas, físicomotoras e múltiplas.

a) Deficiências sensoriais são aquelas em que há perdas significativas na capacidade dos sistemas de percepção. Essas deficiências ocorrem nos diferentes sistemas perceptivos: orientação, háptico, visual, auditivo e palatoolfativo. Esses sistemas, quando alterados, podem gerar dificuldades para que o indivíduo perceba as informações do meio ou aquelas provenientes de outras pessoas, o que torna difícil, principalmente, sua orientação e comunicação.

b) Deficiências cognitivas afetam as atividades mentais e causam dificuldades na compreensão e tratamento das informações recebidas. Comprometem os processos de 
aprendizado, comunicação linguística e interpessoal. O indivíduo com deficiência cognitiva pode apresentar problemas de raciocínio, memória e concentração, e isso dificulta sua aprendizagem, utilização da linguagem oral e escrita e convívio social.

c) Deficiências físico-motoras são aquelas que alteram a capacidade de realização de atividades que exijam força física, coordenação motora, precisão de movimentos e deslocamento de um indivíduo. Diversos fatores podem ser responsáveis pela alteração nos movimentos de uma pessoa: lesões, má-formação ou paralisia nos membros superiores e inferiores, presença de dor, falta de tonicidade muscular, entre outros.

d) Deficiências múltiplas são aquelas em que ocorre a associação de mais de um tipo de deficiência. São mais comuns na população idosa devido, por exemplo, à perda parcial da visão, da audição, do equilíbrio e à presença de diferentes patologias. Outro exemplo é a surdo-cegueira, quando o indivíduo possui, simultaneamente, deficiência auditiva e visual.

Qualquer pessoa, em algum momento de sua vida, pode sofrer algum tipo de limitação, seja em suas capacidades físicas, cognitivas, seja nas psicológicas. Cabe salientar que essas limitações nem sempre são decorrentes de deficiências. Assim, dificuldades ou impedimentos em realizar alguma atividade podem resultar das características ambientais. Uma escada, por exemplo, é uma barreira para uma pessoa que utiliza cadeira de rodas. A existência de um elevador não a impede, contudo, de acessar outros pavimentos em um edifício. Uma criança sem apresentar deficiência pode sofrer restrição para realizar uma atividade - acender a luz - se o interruptor estiver fora de seu alcance.

Nesse sentido, o termo restrição é bastante importante quando se trata de acessibilidade. Bins Ely e Dischinger (2009) asseveram que o termo restrição pode ser definido como a dificuldade existente para a realização de atividades desejadas resultantes da relação entre as condições dos indivíduos e as características ambientais. Sua definição é necessária para que espaços acessíveis possam ser projetados não apenas para aqueles que apresentam algum tipo de deficiência, mas para todas as pessoas.

Portanto, as causas das restrições na realização de atividades podem originar das próprias condições dos indivíduos (como presença de uma deficiência, de idade avançada...) ou das condições do meio, demonstrando a importância de bons projetos de ambientes e equipamentos, livres de barreiras, para a inclusão social de todos.
A cidade de Florianópolis, por apresentar potencial turístico, oferece inúmeros hotéis de diferentes tipologias, tanto no tipo de edificação, horizontal ou vertical, quanto no tipo de unidade habitacional: suíte, flat ou condominial. Para se obter uma listagem de todos os hotéis residenciais, entrou-se em contato com a ABIH-SC - Associação Brasileira da Indústria de Hotéis de Santa Catarina, cujos dados são mais confiáveis e seguros.

A ABIH-SC dispõe de uma listagem única com 69 hotéis, sem distinção dos seus tipos: pousadas, hotéis residenciais, hotéis convencionais, entre outros. Isso dificultou bastante a escolha da amostra. Muitos dos hotéis residenciais foram identificados através do nome fantasia: "apart-hotel", "flat"; foi necessário, por conseguinte, contatar a administração de cada um para verificar seu tipo.

Como o objetivo principal da pesquisa era avaliar as condições de acessibilidade em UHs - outros ambientes do hotel não foram analisados -, o principal critério foi selecionar hotéis residenciais que oferecessem unidades ditas acessíveis, ou seja, consideradas em conformidade com a legislação de acessibilidade pela própria gerência do hotel. Além disso, a escolha da amostra privilegiou UHs de hotéis residenciais que possuíssem configuração arquitetônica diferenciada: uma localizada em hotel vertical, e outra, em hotel horizontal. Foi, portanto, o acesso à unidade habitacional a principal diferença entre elas. Outro aspecto considerado foi a localização dos hotéis em áreas distintas da cidade e que tivessem públicos diferenciados - um público interessado em lazer, e outro, em negócios.

Com todos esses critérios de escolha, a amostra ficou reduzida a dois hotéis, um localizado no centro de

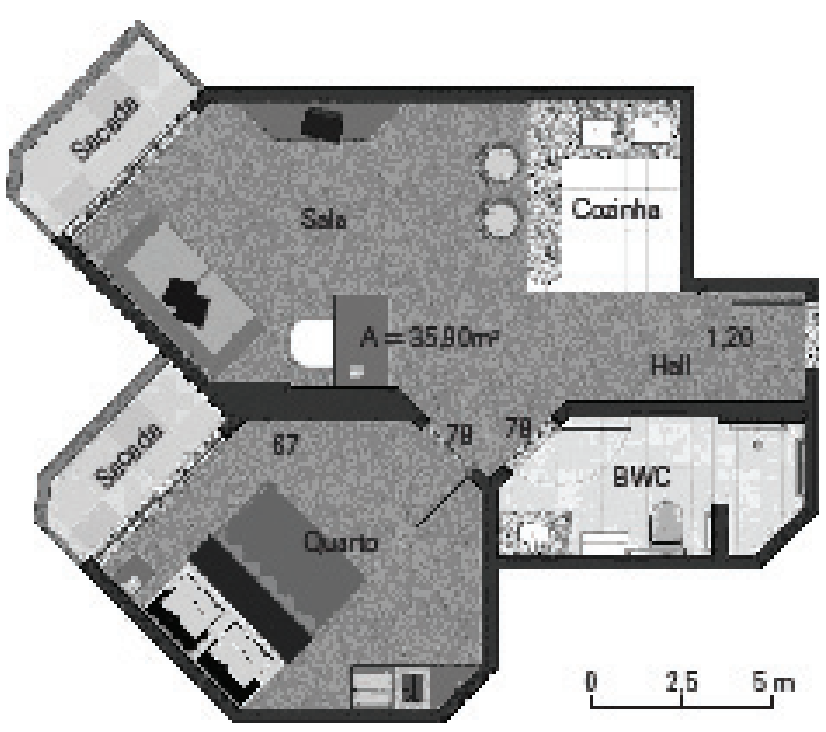

Figura 1: UH A - Hotel A - Situado no centro da cidade. 
Florianópolis, e outro, na praia dos Ingleses, no norte da ilha de Santa Catarina.

O hotel A é um edifício localizado no centro urbano de Florianópolis com 72 UHs e duas delas são consideradas acessíveis. Esse hotel é composto, ainda, por salas para eventos, restaurante, academia e piscina. A UH A (Figura 1), unidade habitacional analisada, é do tipo "apart-hotel", composta por quarto, banheiro, sala de estar, cozinha e sacadas, e totaliza $35,90 \mathrm{~m}^{2}$ de área.

Em geral, UH do tipo apart-hotel é maior que uma UH de hotel convencional e possui copa-cozinha, onde é configurado um espaço para preparo de alimentos. Dessa maneira, o hóspede tem a possibilidade de permanecer hospedado por um período mais longo, uma vez que pode realizar atividades diferentes daquelas desenvolvidas em uma UH convencional, como cozinhar, por exemplo.

O hotel B situa-se na praia dos Ingleses, a $35 \mathrm{~km}$ do centro urbano. Caracteriza-se por possuir unidades habitacionais em edifício vertical e em chalés; possui, no total, 52 unidades, mas apenas um dos chalés é dito acessível. Como é um hotel localizado em praia, destina-se, principalmente, ao lazer e oferece diversas áreas para esse fim: há quadras para prática esportiva,

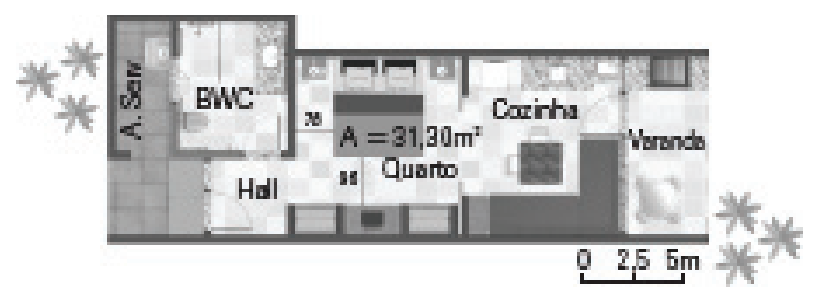

Figura 2: UH B - Hotel B - Situado na Praia dos Ingleses, norte da cidade.

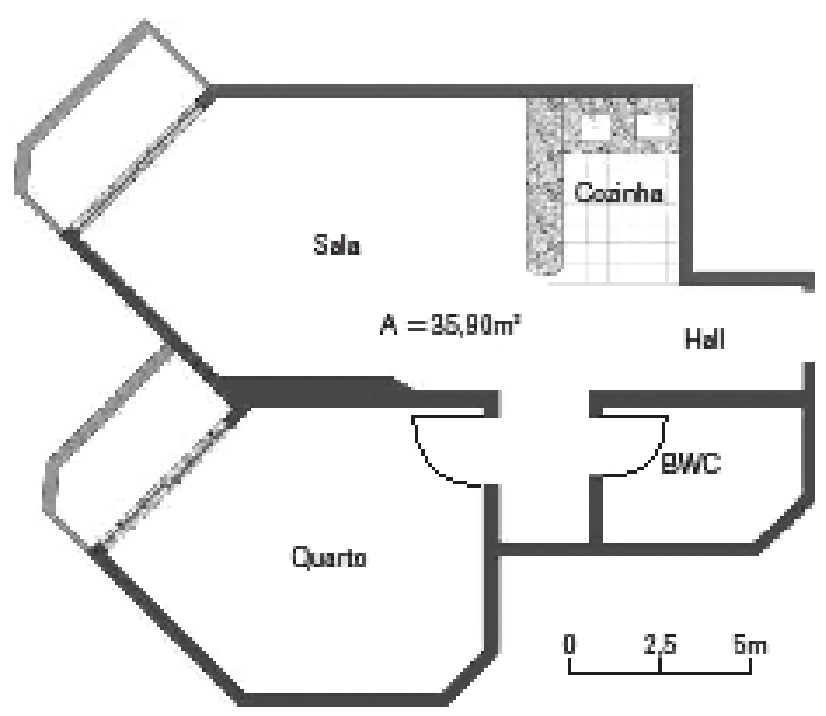

Figura 3: UH A padrão.

Fonte: Autores

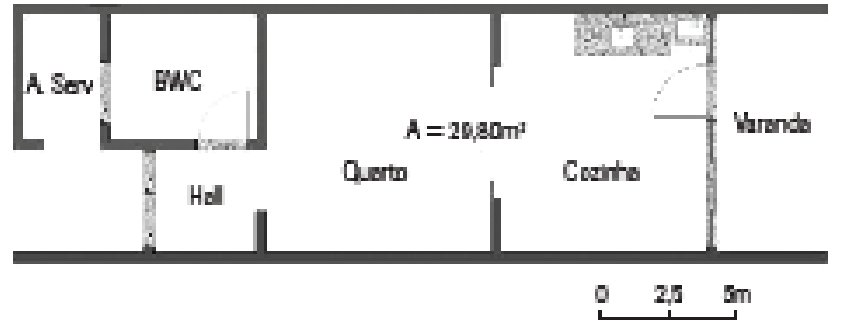

Figura 4: UH B padrão.

Fonte: Autores

piscina, salas de jogos, além de restaurante e salas para eventos. A UH B (Figura 2), unidade analisada deste hotel, é do tipo condominial, composta por quarto, banheiro, estar/jantar, cozinha e varandas; possui, com efeito, área de $31,30 \mathrm{~m}^{2}$.

Leão (1995, apud LEITE, 2004) afirma que uma UH do tipo condominial é semelhante à do tipo apart-hotel no que se refere à configuração interna e aos equipamentos oferecidos, mas é diferente no que diz respeito à composição espacial, uma vez que é uma unidade do tipo chalé, disposta individualmente, geminada ou em fita. O chalé é o tipo de unidade de habitação que mais se aproxima de uma residência unifamiliar.

De acordo com a NBR 9050 (2004), pelo menos 5\% das UHs dos hotéis devem ser acessíveis, mas em ambos os hotéis o número dessas unidades foi menor que esse percentual.

Realizou-se uma comparação entre a UH padrão - sem adaptação - e a UH acessível nos dois hotéis para verificar as implicações em termos de acréscimo de área ou modificação de layout. Na UH A houve apenas reorganização do espaço para aumentar o banheiro; manteve-se, portanto, a mesma área final - 35,90 $\mathrm{m}^{2}$ (Figuras 1 e 3). Já na UH B, pode-se ver que o banheiro foi ampliado, o que resultou no acréscimo de $1,50 \mathrm{~m}^{2}$ (Figuras 2 e 4). Vale lembrar que a área útil considerada nas UHs não inclui varandas e sacadas.

\section{MÉTODOS}

A abordagem adotada nesta pesquisa é qualitativa e caracteriza-se por ser descritiva, uma vez que objetiva descobrir e observar fenômenos a partir da descrição, classificação e interpretação dos dados. Cabe salientar, ainda, que esta pesquisa descritiva apresenta a forma de estudo de caso e procura avaliar, num enfoque sistêmico, a relação entre usuário $\times$ atividades $\times$ ambientes, cuja metodologia baseia-se na intervenção ergonomizadora.

Os métodos utilizados neste estudo foram visitas técnicas e exploratórias, entrevistas com grupos focais e entrevistas individuais. As visitas tiveram o objetivo de avaliar o ambiente arquitetônico quanto à acessibilidade, e as entrevistas procuraram identificar as necessidades espaciais dos diferentes usuários na realização de atividades, de acordo 
com suas habilidades e dificuldades. Assim, nessa abordagem qualitativa, os dados obtidos com a aplicação dos métodos foram tratados a partir de análises de conteúdo.

\subsection{Visita técnica e exploratória}

As visitas técnicas e exploratórias, realizadas para verificar a atual condição de acessibilidade espacial das UHs escolhidas, permitiram identificar os principais problemas e relacioná-los com o que é estabelecido como ideal pela NBR 9050/2004.

Para a realização das visitas, foi necessário fazer contato com as gerências dos hotéis a fim de conseguir permissão a partir de um termo de consentimento. Não houve, todavia, qualquer tipo de dificuldade e, inclusive, foi permitido o registro fotográfico.

Devido à inexistência de qualquer material impresso dos projetos, como plantas baixas ou cortes, efetuou-se um levantamento arquitetônico de cada unidade, assim como de todo o mobiliário. Para a realização dessa etapa, foram utilizadas, principalmente, trena e máquina fotográfica, e elaborados desenhos e anotações em papel. A coleta dos dados demorou cerca de uma hora e trinta minutos em

Tabela 1: Grupos focais.

\begin{tabular}{ccc}
\hline & DEFICIÊNCIAS & INSTITUIÇÃO \\
\hline Grupo 1 & Múltiplas - idosos & NETI/UFSC \\
Grupo 2 & Múltiplas - idosos & Igreja Luterana Campinas \\
Grupo 3 & Físico-motora & AFLODEF \\
Grupo 4 & Sensorial auditiva & ASGF \\
\hline
\end{tabular}

Fonte: Autores

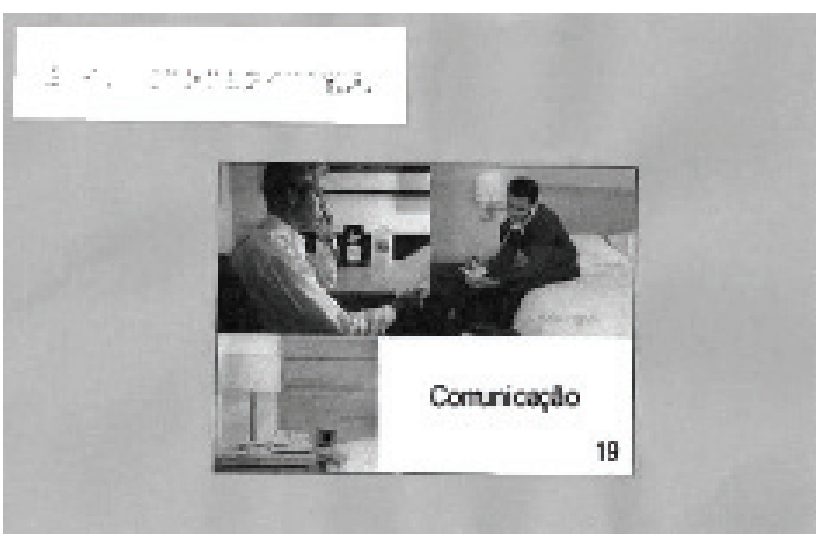

Figura 5: Exemplo de ficha utilizada nas entrevistas. No retângulo branco na parte esquerda superior encontra-se a descrição da atividade em Braille. Fonte: Pinto (2007). cada UH. Posteriormente, os desenhos foram transferidos para um programa $\mathrm{CAD}$, que permitiu ilustrar as $\mathrm{UHs}$, como visto nas figuras $1,2,3$ e 4 .

\subsection{Entrevista com grupos focais}

A entrevista com grupos focais (FREITAS; OLIVEIRA, 1998) é um método utilizado para ampliar o conhecimento de um problema. Nesta pesquisa, teve o papel de aprofundar o assunto referente às dificuldades encontradas pelos usuários na utilização das unidades habitacionais. Além disso, permite saber de que maneira as barreiras poderiam ser eliminadas ou minimizadas, de forma que o usuário pudesse usar o ambiente com conforto e independência.

Esse tipo de entrevista é realizado com um grupo de pessoas que possuem características semelhantes - somente idosos ou crianças ou deficientes visuais. Desse modo, evita-se o constrangimento entre os participantes, especialmente quando mostram suas reais dificuldades.

A partir de contatos com associações de deficientes e instituições, foi possível realizar quatro entrevistas (Tabela 1): com idosos participantes do Núcleo de Estudos da Terceira Idade da Universidade Federal de Santa Catarina (NETI/UFSC) e de uma comunidade religiosa; com pessoas deficientes físicas da Associação Florianopolitana de Deficientes Físicos (AFLODEF); e com pessoas deficientes sensoriais auditivas da Associação de Surdos da Grande Florianópolis (ASGF).

Uma das exigências para participar das entrevistas era possuir experiência em hospedagem a fim de que todos pudessem tratar do assunto com conhecimento prévio.

Desse modo, a técnica utilizada neste estudo foi Avaliação de Ambientes Através de Imagens (REHAL; BIRGERSSON, 2005); aplicaram-se as imagens já utilizadas por Pinto (2007), com algumas modificações. Obteve-se um total de 27 imagens, que se referem às atividades realizadas em unidades habitacionais de hotéis residenciais, como cozinhar, abrir porta, tomar banho, ler, entre outras.

As imagens foram impressas em papel-cartão com suas respectivas legendas e também em braile. Dessa maneira, as imagens eram apresentadas em forma de fichas $(25 \times 16,5 \mathrm{~cm})$ fáceis de serem manipuladas e enumeradas de 1 a 27 (Figura 5). Fez-se, ainda, uso de um gravador para registrar todas as informações fornecidas pelos participantes.

As entrevistas iniciavam com uma breve explicação do objetivo do método e, em seguida, os participantes preenchiam um formulário, no qual informavam sua idade, nível de escolaridade, limitações apresentadas na realização de atividades etc. A seguir, cada entrevistado escolhia de duas a quatro imagens de atividades que lhe remetessem a alguma dificuldade encontrada durante 
sua hospedagem. Isso facilitou, com efeito, a identificação do problema.

Depois da escolha das imagens, alguns questionamentos eram realizados pelo entrevistador para cada um dos entrevistados: "Por que escolheu a imagem?", "O que ela representa para você?", "Consegue realizar a atividade?", "Por que não consegue?" Após um participante ter falado de sua imagem, os outros complementavam e/ou relatavam as próprias experiências na mesma atividade, o que proporcionou maior interação entre eles e mais conhecimento sobre o tema. Como resultado da discussão e devido à concordância das opiniões em relação aos problemas mencionados, os entrevistados puderam apontar diversas soluções que facilitariam a realização das atividades.

Cada entrevista durou cerca de uma hora, tempo considerado suficiente para realizar o processo e para que os participantes não se sentissem cansados ou aborrecidos. $\mathrm{O}$ número de integrantes por grupo variou entre quatro e cinco pessoas, e isso proporcionou boa troca de experiências e relatos importantes.

\subsection{Entrevistas individuais}

Apesar da intenção de se trabalhar exclusivamente com os grupos focais, entrevistas individuais foram efetuadas por não ter sido possível, mesmo com a ajuda da ACIC Associação Catarinense para Integração do Cego, montar um grupo com, no mínimo, três pessoas deficientes visuais.

Desse modo, as entrevistas foram realizadas com duas pessoas cegas em momentos distintos: a primeira foi com o próprio presidente da ACIC; e a segunda, com uma pedagoga, vinda do Rio de Janeiro para proferir palestras nessa associação. Utilizaram-se, portanto, as mesmas imagens das entrevistas com grupos focais, porém, devido à presença de apenas um participante em cada entrevista, foi possível abordar o dobro de imagens com cada entrevistado. Apesar da impossibilidade de discutir em grupo os problemas apontados, a ampla experiência em hospedagem dos dois participantes também permitiu a recomendação de eficientes soluções espaciais para tais problemas.

\section{RESULTADOS}

\subsection{Das visitas}

Para verificar se as unidades habitacionais estavam realmente acessíveis, fizeram-se comparações entre as dimensões encontradas nesses ambientes e no mobiliário com aquelas estabelecidas como ideal pela NBR 9050/2004. Além das dimensões, foram verificados os tipos de mate- riais empregados quanto a sua cor, textura, e a ausência ou inadequação de equipamentos exigidos pela norma.

Para o tratamento qualitativo desses dados, os problemas apontados foram classificados segundo os quatro de componentes da acessibilidade espacial, o que possibilitou identificar as inadequações quanto à orientação espacial, ao deslocamento, ao uso e à comunicação. Os resultados das duas visitas exploratórias foram agrupados, o que permitiu que se fizessem comparações entre as unidades (ver Tabela 2). Detalham-se, a seguir, as inadequações encontradas nas unidades pesquisadas.

\section{? Orientação espacial}

Em ambas as UHs não se constatou a presença de informações em braile, sonoras ou visuais. Salienta-se que os textos contendo orientações, instruções de uso de ambientes, objetos ou equipamentos, regulamentos e normas de conduta e utilização devem estar escritos em braile. Nas duas UHs, o tarifário foi o único tipo de comunicação escrita encontrado, com letras pequenas, que dificultam a leitura por pessoas com limitações visuais.

Com relação às cores dos ambientes, pelo fato de o carpete da UH A ser de cor diferente da parede, há contraste entre esses dois planos e isso facilita que uma pessoa com baixa visão oriente-se nesse espaço. Na cozinha e no

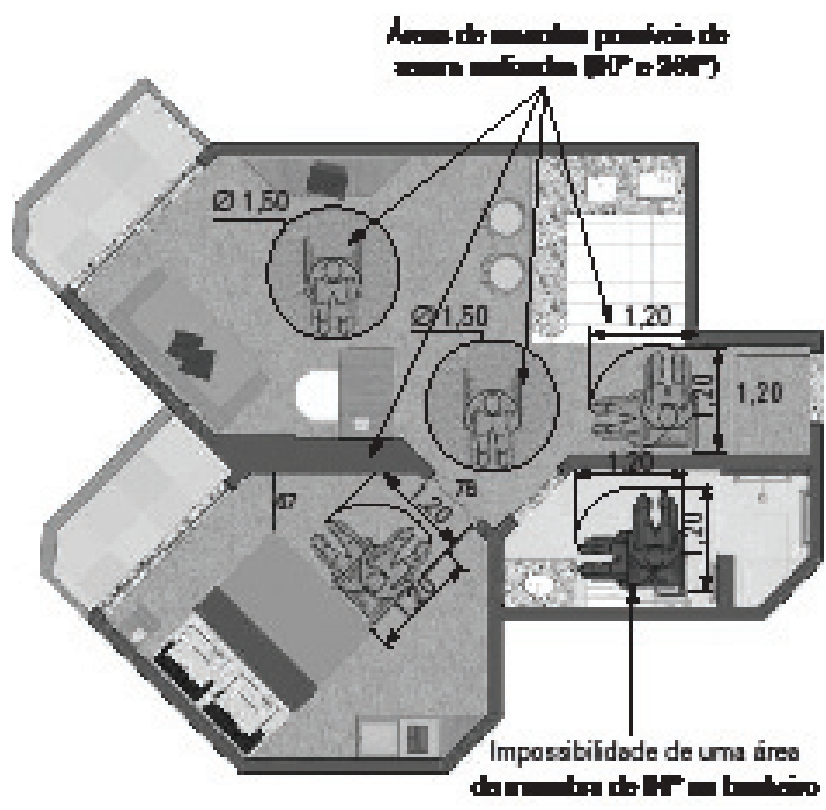

Figura 6: Áreas de manobra na UH A. Nota-se que no banheiro é impossível realizar até mesmo uma manobra de $9^{\circ}$. 
banheiro, essa diferença entre piso e parede se mantém. Em todos os ambientes da UH B, há contraste entre as cores do piso cerâmico e da parede.

\section{Deslocamento}

Analisando o espaço disponível entre o mobiliário da sala de estar da UH A, verifica-se que ele permite a boa circulação de uma pessoa que utiliza cadeira de rodas, e apresenta quatro áreas de manobra - duas de $360^{\circ}$ e duas de $90^{\circ}$ (Figura 6).

Já no quarto, apesar de ser possível efetuar manobra de $90^{\circ}$, a circulação no ambiente é insuficiente, uma vez que o vão de acesso à sacada é de $68 \mathrm{~cm}$, inferior a $80 \mathrm{~cm}$, mínimo exigido pela norma nesse caso (Figura 7). A pior situação

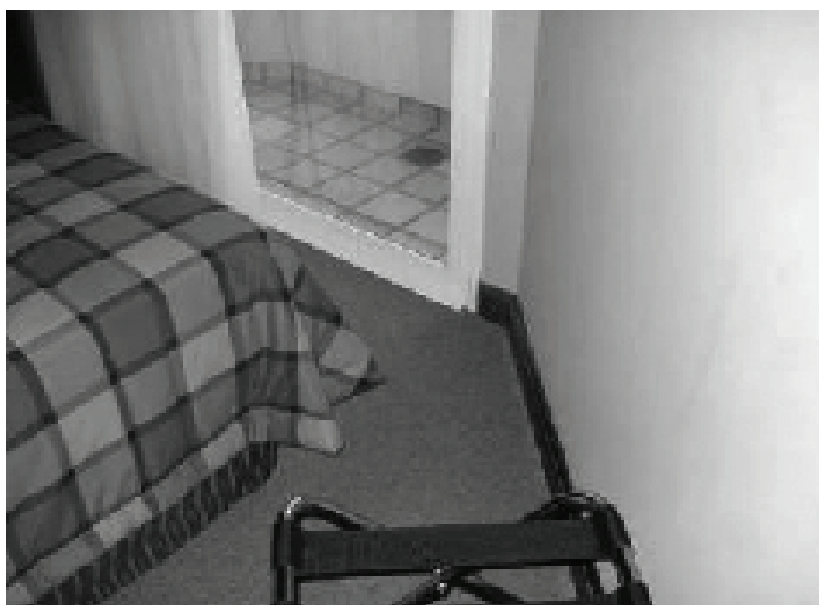

Figura 7: Vão de acesso à sacada - quarto da UH A.

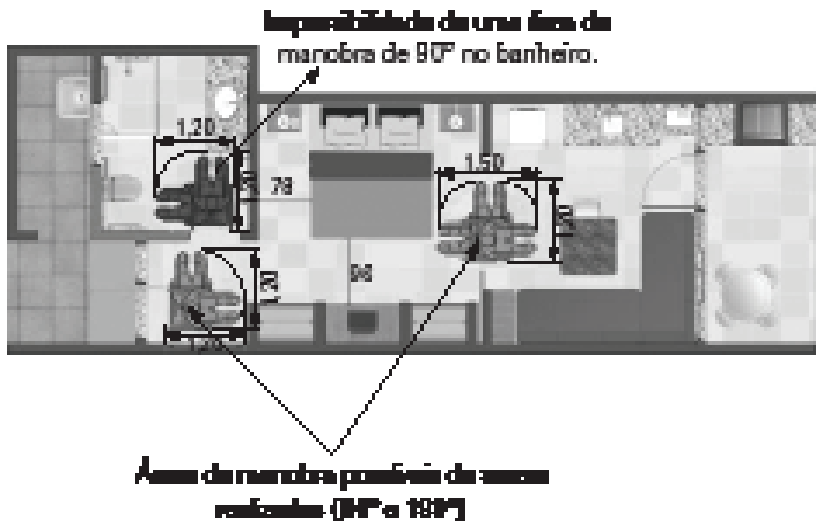

Figura 8: Áreas de manobra na UH B. Nota-se que no banheiro também é impossível realizar uma manobra de $\mathbf{9 0}^{\circ}$. de deslocamento diz respeito ao banheiro, pois não há, ao menos, uma área de manobra de $90^{\circ}$, o que obriga o usuário de cadeira de rodas a entrar de frente e sair de costas. Isso dificulta, sobremaneira, a utilização desse espaço.

A UH B possui uma área de manobra de $180^{\circ}$ no limite entre o quarto e a sala (Figura 8). É possível, no entanto, ter uma área de manobra de $360^{\circ}$ se a mesa da cozinha for deslocada na direção da porta que acessa a varanda. Essa UH apresenta ainda uma área de manobra de $90^{\circ}$ no hall de entrada. O deslocamento de uma pessoa que utiliza cadeira de rodas em torno da cama é dificultado, uma vez que as dimensões dos vãos das laterais são menores que $90 \mathrm{~cm}$, o ideal segundo a norma. No banheiro, verificou-se a inexistência de qualquer tipo de área de manobra, o que prejudica o acesso e uso de equipamentos por uma pessoa que utiliza cadeira de rodas.

\section{Uso}

O uso de alguns móveis e aparelhos eletroeletrônicos é prejudicado nas duas UHs. Na UH A, a bancada $(\mathrm{h}=110 \mathrm{~cm})$ e a pia da cozinha $(\mathrm{h}=102 \mathrm{~cm})$ possuem altura superior ao intervalo estabelecido pela norma: entre $75 \mathrm{e}$ $85 \mathrm{~cm}$ (Figura 9). O aparelho de micro-ondas está em altura adequada; o frigobar está, contudo, localizado no chão, por isso fica fora do alcance confortável do usuário que utiliza cadeira de rodas. As prateleiras, situadas logo acima da pia da cozinha, também estão fora do alcance confortável, uma vez que apresentam alturas superiores a $1,50 \mathrm{~m}$. Não há altura livre inferior para aproximação de uma cadeira de rodas em frente à pia, pois há um armário. De acordo com a norma, deve ser garantida a condição de circulação, aproximação e alcance dos utensílios em cozinhas de hotéis.

Verificou-se, na UH B, que a mesa da cozinha e o aparelho de micro-ondas permitem a aproximação frontal por apresentar vão livre mínimo exigido. O pé da mesa dificulta, no entanto, essa aproximação por possuir base muito grande. Na pia da cozinha (Figura 10) e na da varanda não
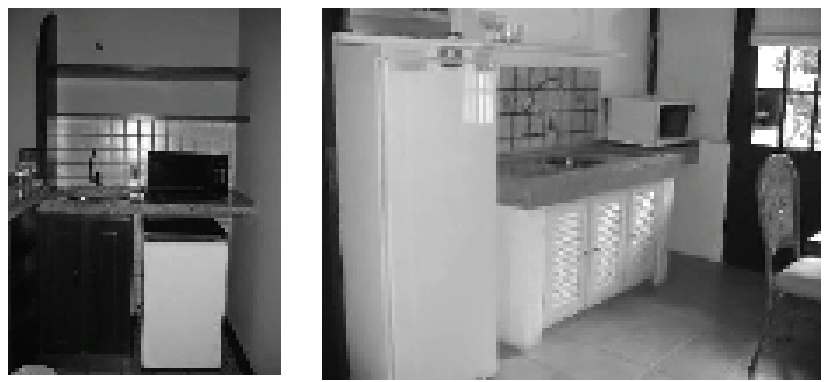

Figuras 9 e 10: Esquerda, cozinha da UH A e direita, cozinha da UH B. 
é possível, contudo, a aproximação frontal devido à existência de armários onde são guardadas louças e utensílios. As prateleiras estão, igualmente, fora do alcance confortável.

Os maiores problemas com relação ao uso nas UHs foram encontrados nos banheiros. Nenhuma das barras de apoio, tanto as localizadas junto ao vaso sanitário quanto as localizadas no boxe, possui as dimensões estabelecidas pela norma (Figuras 11 e 12). O boxe de ambas as UHs não apresenta qualquer tipo de banco, seja articulável, seja removível, necessário para que uma pessoa que utilize cadeira de rodas tome banho. Vale lembrar que esse tipo de banco auxilia, também, os idosos na realização dessa atividade. Os boxes apresentam dimensões inferiores à mínima exigida, a saber: $90 \times 95 \mathrm{~cm}$.
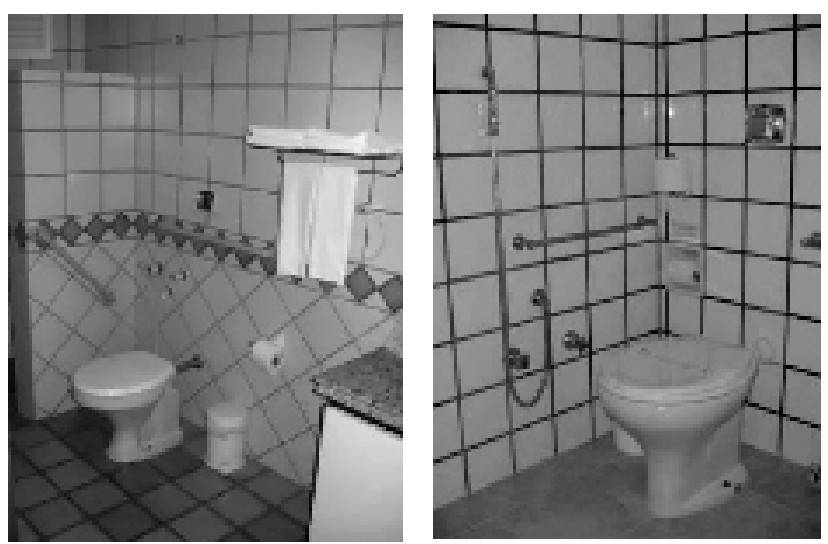

Figuras 11 e 12: À esquerda, banheiro da UH A e à direita, banheiro da UH B.

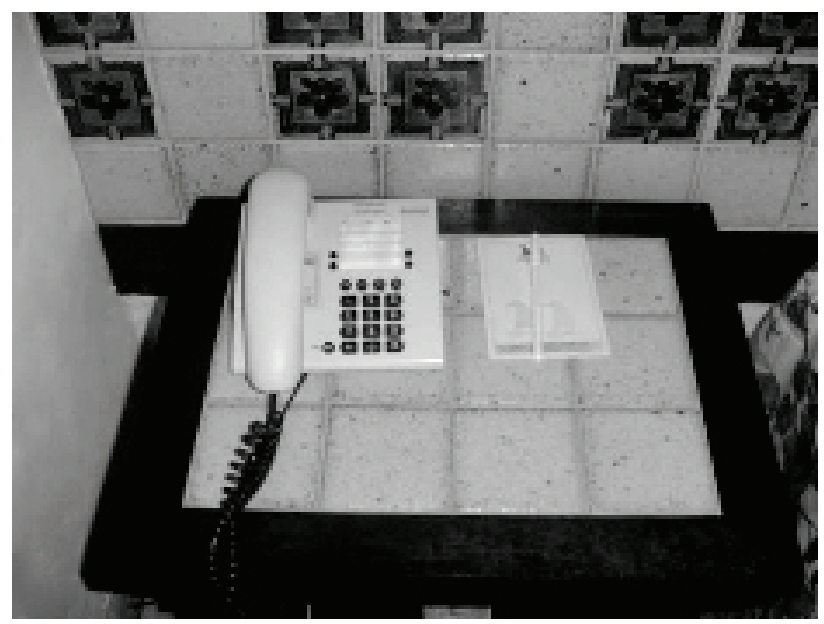

Figura 13. Telefone comum na UH B - sem controle de volume de som.

\section{Comunicação}

Não se constatou a presença de telefones com controle de volume de som e sinal luminoso em nenhuma das duas UHs, embora seja obrigatório em meios de hospedagem (Figura 13).

A seguir, na Tabela 2, organizou-se uma síntese, na segunda coluna, dos problemas identificados. Os pictogramas das colunas 3 e 4 identificam na cor vermelha quando os problemas são encontrados em cada UH. Na $5^{a}$ coluna, logo após identificar o item correspondente em seu sumário, descreve-se o que é estabelecido pela norma.

\subsection{Das entrevistas}

Os problemas mais recorrentes relatados pelos usuários na sua experiência em hospedagem em diversos hotéis foram tratados por análise de conteúdo e organizados nas Tabelas 4, 5, 6 e 7, a seguir. Ressalta-se que tanto os problemas quanto as sugestões dizem respeito a qualquer $\mathrm{UH}$ em que os entrevistados tenham se hospedado; podem, no entanto, ter sido encontrados, também, na amostra durante as visitas realizadas. As atividades, os problemas e as sugestões foram classificados de acordo com o componente da acessibilidade a que se referem (colunas 2, 3 e 4 das Tabelas 4, 5, 6 e 7).

$\mathrm{Na}$ última coluna de cada tabela, estão representados por pictogramas (ver legenda da Tabela 3) os diferentes entrevistados, cuja opinião encontra-se descrita na linha correspondente.

\section{CONCLUSÃO}

Destaca-se, em primeiro lugar, que a aplicação de diferentes métodos evitou que a pesquisa ficasse restrita às limitações de cada um, o que possibilitou sua complementação e contribuiu para a identificação da natureza dos problemas levantados nas UHs. As visitas exploratórias apontaram inadequações dos ambientes, mobiliários e equipamentos quando comparados aos parâmetros técnicos da NBR 9050. As entrevistas permitiram, todavia, o conhecimento de problemas que não poderiam ser detectados apenas com essas visitas, pois ainda não estão contemplados pela norma. Esses problemas dizem respeito, em sua maioria, às dificuldades enfrentadas pelos usuários com deficiência sensorial auditiva e visual. Isso comprova que, apesar das revisões das últimas duas décadas, a NBR 9050 ainda está direcionada a atender principalmente necessidades de deficientes físico-motores. É fundamental, por conseguinte, contar com a experiência de diversos usuários que sofrem restrições no uso dos espaços para ampliar o 
Tabela 2. Quadro síntese dos problemas encontrados nas UHs.

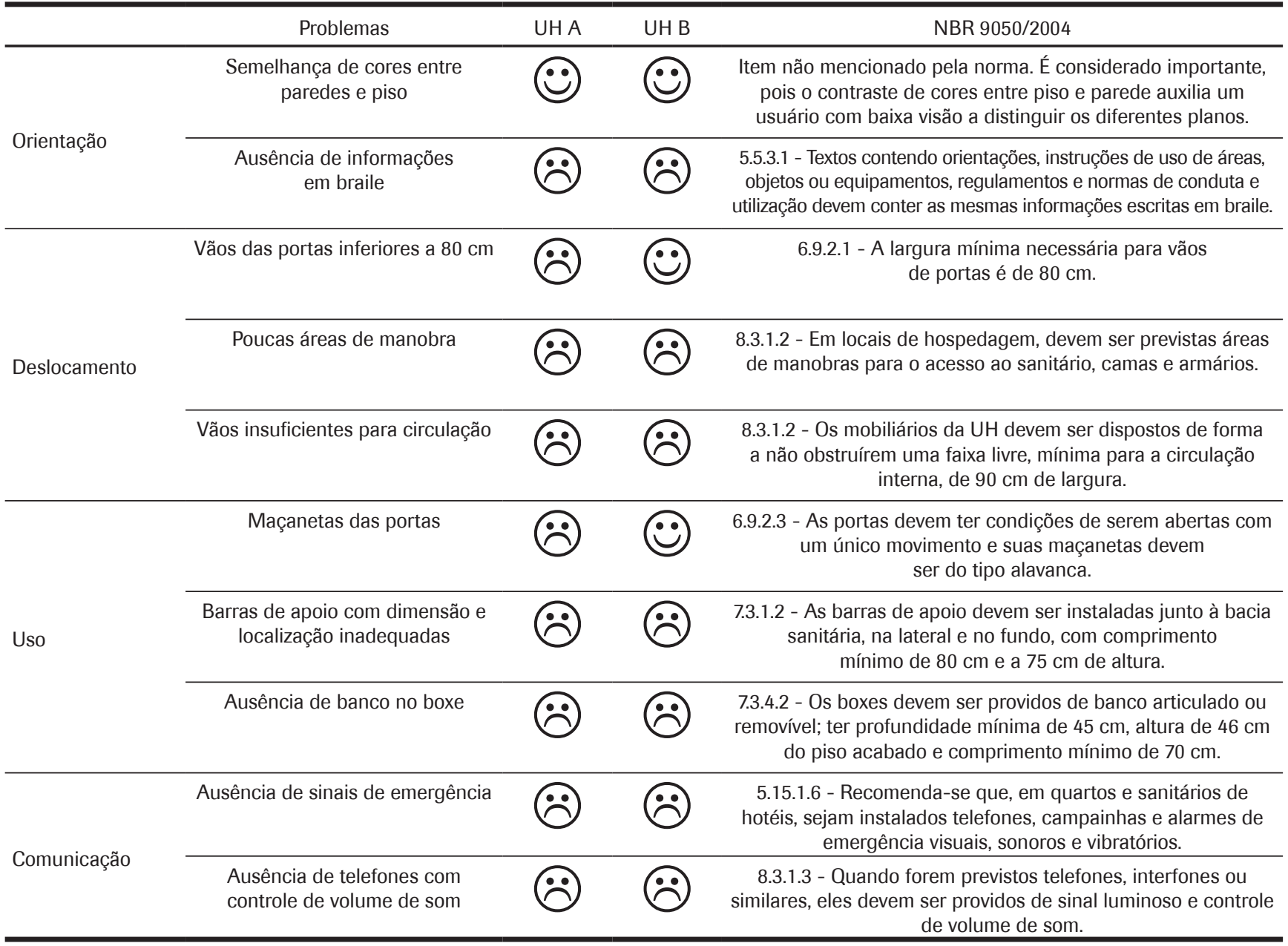

Fonte: Autores

Tabela 3. Legenda dos usuários entrevistados.

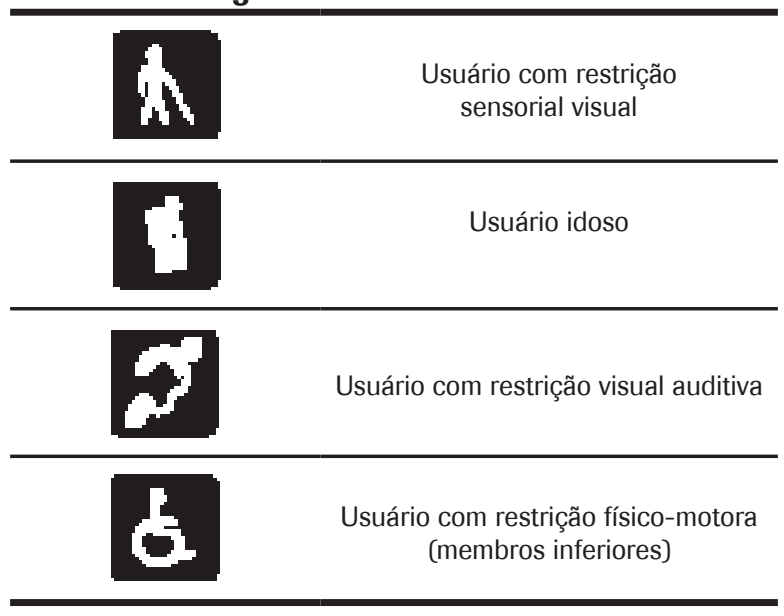

Fonte: Autores 
Tabela 4. Quadro síntese dos problemas relacionados à orientação.

Orientação espacial

\begin{tabular}{|c|c|c|c|}
\hline Atividade & Problema relatado & Sugestão & Usuário \\
\hline $\begin{array}{l}\text { Orientar-se quando há } \\
\text { falta de luz }\end{array}$ & $\begin{array}{l}\text { Não há como localizar-se } \\
\text { no hotel quando há falta de } \\
\text { luz, pois o usuário, além de } \\
\text { não ouvir, também não } \\
\text { poderá ver. }\end{array}$ & $\begin{array}{l}\text { As dependências do hotel, } \\
\text { principalmente as UHs, devem estar } \\
\text { equipadas com luz de emergência. }\end{array}$ & \\
\hline $\begin{array}{c}\text { Compreender a } \\
\text { organização da UH }\end{array}$ & $\begin{array}{l}\text { Não há como saber a } \\
\text { localização de cada } \\
\text { ambiente e a disposição do } \\
\text { mobiliário }\end{array}$ & $\begin{array}{c}\text { É necessário que um funcionário do } \\
\text { hotel explique, detalhadamente, o } \\
\text { layout da UH. }\end{array}$ & \\
\hline
\end{tabular}

Fonte: Autores

Tabela 5. Quadro síntese dos problemas relacionados ao uso.

\begin{tabular}{|c|c|c|c|}
\hline Atividade & Problema relatado & Sugestão & Usuário \\
\hline Utilizar armários & $\begin{array}{l}\text { Dificuldade em utilizar armários } \\
\text { altos, pois exigem mais esforço. }\end{array}$ & $\begin{array}{l}\text { Os armários e prateleiras devem } \\
\text { ser instalados em altura adequada. }\end{array}$ & \\
\hline Tomar banho & $\begin{array}{l}\text { O uso de cortina plástica como } \\
\text { proteção não impede que a água } \\
\text { molhe todo o banheiro. }\end{array}$ & $\begin{array}{c}\text { A área do boxe deve ter bom } \\
\text { escoamento e dois ralos para } \\
\text { captar a água. }\end{array}$ & \\
\hline Tomar banho & $\begin{array}{l}\text { Uso de bancos plásticos soltos, } \\
\text { no boxe, pode causar a queda do } \\
\text { usuário. }\end{array}$ & $\begin{array}{l}\text { Fazer uso de bancos fixos } \\
\text { na parede e articulados com } \\
\text { superfícies antiderrapantes. }\end{array}$ & \\
\hline Apoiar-se & $\begin{array}{l}\text { Ausência de barras de apoio } \\
\text { pode causar quedas. }\end{array}$ & $\begin{array}{l}\text { Devem ser instaladas barras de } \\
\text { apoio junto ao lavatório, vaso } \\
\text { sanitário e boxe. }\end{array}$ & \\
\hline Utilizar torneiras & $\begin{array}{c}\text { Quando há opção de água quente } \\
\text { e fria, nem sempre é possível } \\
\text { identificá-las. }\end{array}$ & $\begin{array}{c}\text { Manter o padrão de água quente } \\
\text { do lado esquerdo e água fria do } \\
\text { lado direito. }\end{array}$ & \\
\hline Utilizar torneiras & $\begin{array}{l}\text { Torneiras giratórias dificultam } \\
\text { a utilização, pois exigem maior } \\
\text { esforço e coordenação. }\end{array}$ & $\begin{array}{c}\text { Fazer uso de torneiras que exijam } \\
\text { pouco esforço, como torneiras } \\
\text { monocomando. }\end{array}$ & \\
\hline Abrir portas & $\begin{array}{c}\text { Chave da UH do tipo cartão: não } \\
\text { há como saber de que lado ele } \\
\text { deve ser inserido. }\end{array}$ & $\begin{array}{c}\text { Deve-se fazer uma marcação tátil } \\
\text { no cartão para saber como ele } \\
\text { deve estar posicionado. }\end{array}$ & \\
\hline Cozinhar & $\begin{array}{l}\text { Dificuldades em utilizar micro- } \\
\text { ondas e forno elétrico, quando a } \\
\text { UH oferece estes equipamentos. }\end{array}$ & $\begin{array}{l}\text { Deve haver uma marcação tátil, } \\
\text { pelo menos, nos principais botões } \\
\text { a serem utilizados, como "start" }\end{array}$ & \\
\hline
\end{tabular}


Tabela 6. Quadro síntese dos problemas relacionados ao deslocamento.

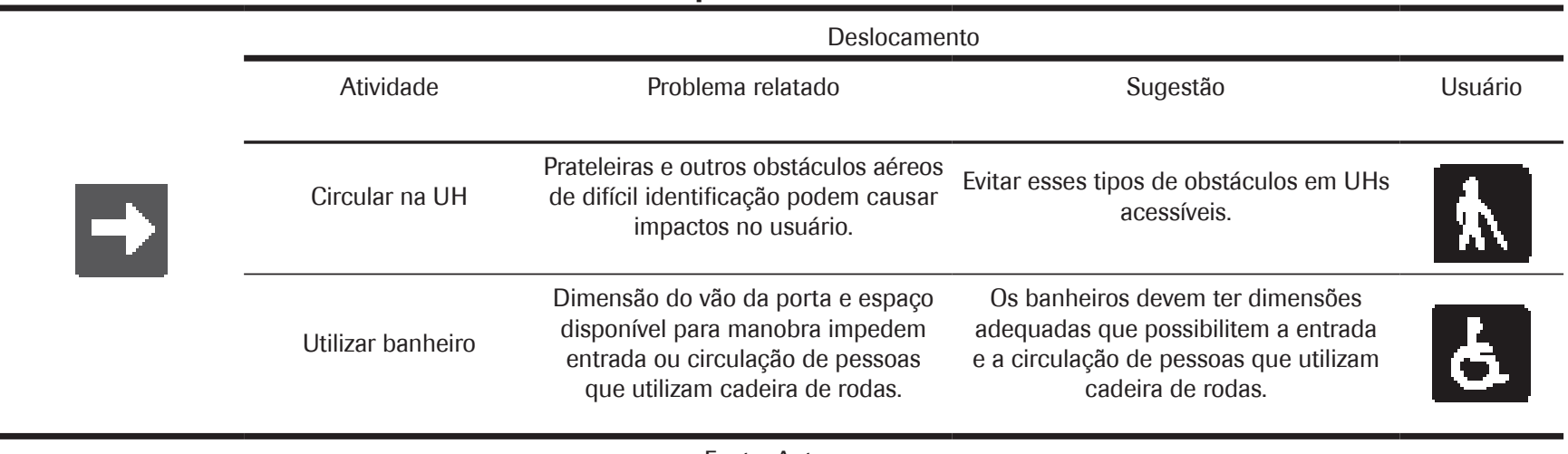

Fonte: Autores

Tabela 7. Quadro síntese dos problemas relacionados à comunicação.

Comunicação

\begin{tabular}{|c|c|c|c|}
\hline Atividade & Problema relatado & Sugestão & Usuário \\
\hline $\begin{array}{l}\text { Ligar para os serviços do } \\
\text { hotel }\end{array}$ & $\begin{array}{l}\text { Ausência de tabela, com os números } \\
\text { dos ramais do hotel, em braile: não há } \\
\text { como comunicar-se com os funcionários } \\
\text { ou solicitar serviço por telefone. }\end{array}$ & $\begin{array}{c}\text { Deve haver uma tabela, com todos os } \\
\text { ramais, em braile e também em letras } \\
\text { ampliadas em relevo, para auxiliar } \\
\text { pessoas com baixa visão. }\end{array}$ & \\
\hline $\begin{array}{l}\text { Comunicar-se com } \\
\text { funcionários no hotel }\end{array}$ & $\begin{array}{l}\text { Comunicação com funcionários do hotel } \\
\text { é difícil quando estes não sabem Libras. }\end{array}$ & $\begin{array}{l}\text { Pelo menos um funcionário do hotel } \\
\text { deve saber Libras. }\end{array}$ & \\
\hline Utilizar o telefone da UH & $\begin{array}{c}\text { Quando precisar de algum serviço do } \\
\text { hotel, não será possível fazer o pedido } \\
\text { em um telefone comum. }\end{array}$ & $\begin{array}{l}\text { Necessidade de um telefone que } \\
\text { transmita informações do quarto para a } \\
\text { recepção através de suas teclas. }\end{array}$ & \\
\hline $\begin{array}{l}\text { Ser informado de } \\
\text { situações de emergência }\end{array}$ & $\begin{array}{l}\text { Não há como saber quando há uma } \\
\text { situação de emergência - incêndio, } \\
\text { por exemplo - uma vez que os } \\
\text { alarmes são sonoros. }\end{array}$ & $\begin{array}{l}\text { Deve haver um sinal luminoso na } \\
\text { UH que indique uma situação de } \\
\text { emergência e a necessidade de sair do } \\
\text { local. }\end{array}$ & \\
\hline
\end{tabular}

Fonte: Autores

conhecimento sobre as diferentes dificuldades enfrentadas e propor soluções adequadas, bem como traduzi-las em normas técnicas.

Com a realização desta pesquisa, foi possível concluir que é urgente melhorar as condições de acessibilidade dos hotéis residenciais. Em algumas situações, vê-se a tentativa de adequação do espaço físico a partir de determinadas intervenções, mas fica claro que são ineficientes. Normalmente, a UH acessível é uma simples adaptação da UH padrão, sem atender às dimensões mínimas estabelecidas, o que exigiria, na maior parte dos casos, um acréscimo de área e modificações do layout. Como consequência, é recorrente a ausência de espaços de circulação e de áreas para manobras, principalmente nos sanitários. Essas dificuldades dizem respeito ao componente "deslocamento" da acessibilidade espacial. Verificou-se, no entanto, maior prevalência de problemas ligados ao componente "uso": o desenho e a localização de mobiliários e equipamentos prejudicam a realização de atividades com conforto e independência.

Infelizmente, a acessibilidade espacial não é, ainda, prioridade: os próprios profissionais responsáveis pelos projetos de ambientes acessíveis desconhecem as reais necessidades das pessoas que sofrem restrições na realização 
de atividades e dificilmente avaliam os ambientes por eles projetados após sua ocupação. Além disso, grande parte da população brasileira desconhece as leis e normas, por isso não reivindica seu direito de participação, na sociedade, com igualdade.

É, portanto, extremamente relevante discutir o tema em escolas de arquitetura e engenharia e, na medida do possível, incluí-lo em seus currículos. No caso específico dos hotéis, a acessibilidade espacial deve, também, ser tratada junto aos órgãos responsáveis, como a Associação Brasileira da Indústria de Hotéis, para que conheçam as reais necessidades em termos de espaços e equipamentos de seus diversos hóspedes.

Cabe, por fim, destacar a inexistência de fiscalização efetiva que exija dos estabelecimentos hoteleiros sua adequação à NBR 9050/2004, o que certamente diminuiria os problemas encontrados e tornaria as UHs compatíveis com as exigências do Decreto n. ${ }^{\circ} 5.296$.

\section{Artigo recebido em 06/02/2009 Aprovado para publicação em 05/08/2009}

\section{REFERÊNCIAS}

Associação Brasileira de Normas Técnicas ABNT. NBR 9050. Acessibilidade de pessoas Portadoras de Deficiência a Edificações, Espaços, mobiliário e Equipamentos Urbanos. Rio de Janeiro, 2004.

Associação Brasileira das Indústrias de Hotéis de Santa Catarina - ABIH - SC. Disponível em: $\langle$ http://www.abihsc.com.br $>$. Acesso em: Novembro 2007.

BRASIL. Decreto $n^{\circ} 5.296$, de 2 de dezembro de 2004. Regulamenta as Leis nos 10.048 , de 8 de novembro de 2000 e 10.098, de 19 de dezembro de 2000. Estabelece normas gerais e critérios básicos para a promoção da acessibilidade das pessoas com deficiência ou com mobilidade reduzida, e dá outras providências. Brasília, 2004.
DISCHINGER, M.; BINS ELY, V. H. M.; MACHADO, R. Desenho Universal nas Escolas: acessibilidade na rede municipal de ensino de Florianópolis. Florianópolis: Grupo PET/Arq/ SESU/UFSC, 2004.

DISCHINGER, M; BINS ELY, V. H. ; PIARDI, S. M. D. G.. Promovendo acessibilidade nos edificios públicos: programa de acessibilidade às pessoas com deficiência ou mobilidade reduzida nas edificações de uso público. Florianópolis, [2009]. Trabalho em andamento.

FREITAS, H. M. R.; OLIVEIRA, M. Focus Group - pesquisa qualitativa: resgatando a teoria, instrumentalizando o seu planejamento. Revista de Administração, v. 33, n. 3, p. 83-91, 1998.
OLIVEIRA, A. S. D. A. de. Acessibilidade espacial em centro cultural: estudo de casos. Florianópolis, 2006. Dissertação (Mestrado em Arquitetura) - Programa de Pós-Graduação em Arquitetura e Urbanismo, Universidade Federal de Santa Catarina.

PINTO, A. C. A. Hotel universal: diretrizes projetuais e de acessibilidade. Florianópolis, 2007. Dissertação (Mestrado em Arquitetura) Programa de Pós-Graduação em Arquitetura e Urbanismo, Universidade Federal de Santa Catarina.

REHAL, S.; BIRGERSSON, L. What' happens when imagery is used to complement speech in dialogues involving changing the built environment? In: INTERNATIONAL CONFERENCE FOR INTEGRATING URBAN KNOWLEDGE \& PRATICE, 2005, Gothenburg.

\section{SOBRE OS AUTORES}

\section{Vera Helena Moro Bins Ely}

Universidade Federal de Santa Catarina - UFSC

Florianópolis, SC, Brasil

E-mail: vera.binsely@gmail.com

\section{Cristiane Silveira da Silva}

Universidade Federal de Santa Catarina - UFSC

Florianópolis, SC, Brasil

E-mail: crix_silveira@yahoo.com.br 